\title{
Seniors, iTV and content about Social Services: Clarifying the relationship
}

\author{
MARIANA CARLOS \& TELMO SILVA, University of Aveiro, Aveiro
}

\begin{abstract}
Over the years, television has been seen as a means of enriching human development. The technological evolution of this means of communication has led broadcasters to deliver more attractive and diversified contents. Hence, traditional broadcasting has evolved from the traditional passivity to the granting of a participatory role for viewers, creating a new paradigm - Interactive Television. Senior citizen viewers are great consumers of television and represent a considerable portion of people, who can take advantage of the interactivity potentialities. Most of the time, changes in social services take too long to reach senior citizens due to their technological, sensory or cognitive limitations, which tend to occur with the aging process. In this exploratory study, the research team aims to find principles for the development of content about social services, considering iTV potential and the limitations of senior citizens' viewers. To accomplish this goal, the research team developed audiovisual content, videos regarding social services with different approaches on technological aspects. The evaluation of its effectiveness was by means of inquiry with direct questions on the material that was showcased.
\end{abstract}

\section{KEYWORDS}

senior citizens, interactive television (iTV), digital television, social services

\section{Introduction}

The aging of the world's population is a reality (Ferreira 2013, 15). The progress in economy and health sectors, as well as the overall improvement of living conditions as comfort, hygiene regulations and safety have made possible one of humanity's greatest desires: longevity (Ferreira 2013, 15).

This experimental procedure seeks to accomplish the forge of a new link that would be of use to connect senior citizens even further to the new technology world, in this case study, interactive television. The goal of this case study is the adaptation of audio visual contents for senior citizens bearing their necessities in mind. To achieve that goal, the research group established research guide-lines that consisted on a three part analyses and data retrieving process: i) showcasing two videos with the same theme, edited in different ways, to senior citizens; ii) questioning the viewer's opinion of both contents showed with a set of pre-made questions; iii) analysing the data retrieved. 
Since the goal of this experimental procedure is to enlarge the role of new technology in senior citizens lives, we have to keep in mind the process of aging and what it implies. With the passing of time, most senior citizens reduce their role in society and the role they take in a community, which can create a feeling of loneliness and self-doubt (Silva $2014,65)$. This feeling may have effects on their social inclusion, family environment and also on their physical and mental health. (Teixeira 2010,4). Aging is a process that occurs in many different ways and not all persons handle it in the same way, it depends on each individual perspective and capabilities in the cognitive and visual aspects, etc. (Silva 2014, 65).

There are physical and physiological changes in the eye structure, which can lead to visual impairment, light sensibility, color blurring, and night vision loss. Hearing loss is also a factor on the aging equation (Cardoso 2009, 1). There is sometimes a considerable loss in sound perception, normally in the lower sound range. These two constants, hearing and visual loss, when put together can lead to social loneliness and depression. (Silva et al. 2013, 145).

Another characteristic that is associated with aging is the movement limitation on the shoulders, something that can appear silently and painlessly (Silva 2014, 66). Due to this limitation, some senior citizens have to spend more time in doing day-to-day tasks, such as: getting dressed, driving, showering, getting to sleep, among many others. This lack in their movement range, associated with hearing and visual impairments, may become a risk of social exclusion that can lead to depression.

Besides physical lacking, there are also the cognitive problems associated with the aging process. It is known that older people can have difficulties in assimilating new information and their reasoning ability is visibly worn out and reduced. Globally, senior citizens have a bigger difficulty in performing some tasks better than others and are more susceptible to loss of information. Beyond the scientific breakthroughs, Silva $(2014,1)$ states that technological discoveries are constantly changing the way society is organized and evolves. Television is one of those discoveries (Silva 2014, 1). Mass communication translates itself into information through social media, particularly television, newspapers, magazines, cinema, radio and, of course, the Internet. Although the Internet has a prime role in society, television is still arguably the greatest means of entertainment and communication. Therefore, television is a means of communication that can leverage interpersonal relations and social cohesion. (Abreu 2007, 23).

Wolton $(1996,16)$ reports that television:

'(...) is an object that incorporates conversation. We speak with each other, and then speak with others away of our homes. In this scenario it is an indispensable social bond in a society where individuals tend to be frequently isolated, and sometimes lonely. It is the only activity that can create an equivalent link between rich 
and poor, young and old, urban and rural lifestyles, a link between learned and non-learned.'

Based on this argument, we can assume that television is seen as a path to construct opinions and to enhance knowledge by the masses. It influences our way of dealing with life in terms of values, traditions and the overall norms (Abreu \& Branco, 1998).

McLuhan's perspective (1962) enhances the revolutionary power that was generated by television and also classifies the means of communication as hot or cold. On one hand, hot means are channels that have high definition standards and are focused on any social target and have the tendency to be very visual, logical and private. On the other hand, cold means have the tendency to be more aural, intuitive and emotionally engaging (Santos, 2003). Hence, McLuhan states that television can be defined as an aural and immersing path that demands participation and involvement. We can work while listening to the radio, but the same situation cannot, with certainty, occur while watching television, because we can do both activities but there is no guarantee both can be done well.

In the television market scene, as in many other communication and social media, the spotlight has been shadowed by the influence of the Internet, either by the existence of web portals (with on-going live feeds of information, radio live streams or contests via live stream) or also by the capability to disseminate personal information content (Silva 2014, 1). The emergence of personal computers and the dissemination of the Internet originated a big technological revolution that with the development of its infrastructure enabled the creation of new services and shifted the already existing media of television to this digital paradigm - Interactive Television (Silva 2014, 1).

In 2011, the Portuguese channel 'Independent Television (TVI)' was pioneer in implementing interactive television with experimental sessions, via cable television. The user started to have access to thematic and complementary information, the control over visual frames and visual angle or even polls (Violante et al., 2015). TV programs that offered viewers the control over an interactive character by using their phone, such as "Hugo" (the first interactive Portuguese TV program) are examples of a simple use of television interactivity. The constant technological evolution together with the constant demand of new services by the TV industry that release them, have potentiated the need and the producing of new services, for instance social security information services and medical information services.

From this point of view, the pertinence of this investigation is indisputable, since aging is a global phenomenon that has induced several deep changes in developed societies. These changes challenge younger generations to develop multiple gerontechnologies (gerontology + technology), which are technologies that meet the senior citizens expectations and needs in their "natural environment". They can help senior citizens people in their social anxieties and general needs. 
Many of the developed technologies have as goal the social inclusion and integration of senior citizens in the already existing communities, enlarging their social network and increasing their levels of well-being and digital literacy. In this context, television rises as an effective way to induce and support dialogue and conversations between people (Abreu 2007, 23). Additionally, as television is arguably the closest and most familiar means of communication to the senior citizens, television can be seen as a more advanced technological service for this population segment. Hence, it can be an important support to older people through various features, such as reducing the distance between them and the social service location, hence bringing them the information without the need to transport to the location.

This idea was to be obtainable trough all kinds of social services, such as support of services that promote social interaction and collective viewing, the provision of medical information or, as is the goal of this proposal, the information dissemination on public services relating to society. (taken from: project proposition +TV4E, 2015). Besides the important investment of public administration in disseminating the public and social services, these services are still not correctly thought out and drawn to the needs of this specific public (senior citizens). Due to this fact senior citizens people are commonly found in a disadvantaged position, for not knowing how to access public services and assistances they can benefit from (e.g. medication discounts, medical appointments, etc.), thus, there is often a high informational dependence on their caregivers' network.

In this framework, this paper aims to enumerate a set of variables and principles for the orientation of audiovisual content that respects the specificities, needs and expectations of the target audience, so senior citizens may be fully informed about the numerous changes that occur in social services, in a short period of time.

\section{Guidelines}

In a first trial, a preliminary test was carried out with 8 senior citizens (ages between 55 and 75). It was possible to confer some of the aspects described in Fisk et al (2009), Zaphiris, Ghiawadwala and Mughal (2005) and in Caldas $(2014,33)$ for the conceptualization of audiovisual contents: (a) Avoid decorative fonts (example: Gothic, Rosewood and Old English), so the use of Arial or Verdana is advised; (b) Reach a contrast of 50:1 (example: black text on white background or vice-versa); (c) Avoid the movement of text (scrolling); (d) Use only 140 words per minute (pausing in speech is essential); (e) Consider the contexts in which male voices (ads) and female voices (for drawing attention) are used; (f) Minimize the background sound and eco and; (g) Avoid background music while audio content is delivered.

In this context, the following recommendations should be equally held in mind (Czaja \& Sharit, 2012), due to their prior use in recent studies with the same target audience: (a) Do not overcharge the senior's visual channel, so replacing the use of text for narra- 
tion is recommended; (b) The speed of narration should be slow or moderate, thus not overwhelming the cognitive capacity of the senior is recommended; (c) Avoid audio information overload; (d) Not overcharging the senior with visual and audio information simultaneously; (e) It is imperative that the narrator's voice transmits calm as well as preventing possible fears; (f) Using narration to direct the user's attention to visualization of given information and; (g) Avoid formal conversation.

\section{Research Process}

In order to understand the relationship between the best approaches to create audiovisual content and senior's specific requirements, a set of interviews and tests with a target audience was carried out. This exploratory study will be helpful to inform the next steps of the + TV4E project.

During the evaluation and data retrieving process, it was necessary to create 2 different groups with 8 elements in each one. Each participant was asked to evaluate two videos on the available topics. In this case, the available topics were: 1) the process of billing validation through the eFatura portal; and 2) the driving license regulated by a points system. After the topic selection, which was dependent on the senior's interest, a brief questionnaire about their personal data, age, professional career and the structure of their family was presented.

After that, the interview proceeded with questions related to television habits, types of audiovisual devices existing in the family household and the overall level of digital literacy. To characterize digital literacy, the metrics defined in Digital Literacy European Commission Working Paper and Recommendations from Digital Literacy High-Level Expert Group (European Commission, 2008, 5) were used. Thus, it is necessary to know if a person was able to: (a) Copy or move a file or a directory; (b) Use the copy and paste tools to copy or move information within a document; (c) Use arithmetical formulas in a spreadsheet; (d) Compress files; (e) Connect and install new devices (for example: a printer); (f) Use the search engine; (g) Send an e-mail with attached files; (h) Post messages on discussion groups, forums and chats; (i) Use the Internet for phone calls; (j) Share movie files and music files with other users; (k) Create a web page and; (l) Develop a software app using a programing language.

In short, a person has high digital literacy if is able to execute five or more of these tasks, medium digital literacy when is able to execute three or four and low digital literacy when is only able to execute up to two of these tasks.

Then, the physical capabilities (auditory and visual) of the participant were tested, as well as their cognitive capabilities (memory and concentration). To evaluate physical capabilities, we asked the participant about their physical limitations. Furthermore, it was informed to all who took part in the study on the importance of truthfulness of their answers, and that only the authors would have access to them, they were then informed 
of their anonymity towards the general public. On the other hand, to evaluate the cognitive capabilities we carefully studied their speech looking, indirectly, for faults this based on previews studies.

It was important to perceive which social services the senior had more interest in obtaining information on, what were their greatest doubts and how, normally, they get information about social service changes (for example: did you know that in 2016, the age of retirement went up to 66 years and 2 months. If is the case how you got hold of this information through television, newspapers and radio?). Before this, it was imperative to perceive the level of difficulty that the senior had in utilizing this kind of media and to try and minimize the changes to it the least as possible.

Upon finalizing the first part of the questionnaire, already described, it was time to present the first video. After the video we proceeded with a set of questions related to the contents showed. This set of questions was repeated after the visualization of the second video, to enable the adequate evaluation of the video construction. The evaluation contained questions regarding the font size (if it was readable or not), the image quality, audio quality and if the video was or was not appealing. Secondly, it was necessary to know if the information was clear to perceive, or if there were issues that created difficulty in the video perception and the understanding of information, such as sound volume (too high/ to low), text reading (font too big/small), video length (too long/short), and the use of complex words.

Some questions about the presented video were then asked in order to test the concentration capability and the clarity of the delivered information. Lastly, the senior had to choose between the first and the second video, justifying his choice.

Simultaneously, the standardized scale SAM (Self-Assessment Manikin) (Lang, 1980) was used as a complement. The SAM is considered a non-verbal, pictograph and simple application test. The SAM scale presents three pictographically scales and each one is composed of a sequence of five or nine drawings, graded in intensities, which represent different levels of emotional dimensions (pleasure, arousal and dominance). The pleasure dimension is represented at one end by an unhappy and bored figure and at the other end by a happy smiling figure (Leão 2012, 20). Thus, the classification of arousal goes from the state of relaxation or ease (represented by a relaxed figure with closed eyes) to excitement (represented by an activated figure with wide and open eyes) (Leão 2012, 69). Lastly, the dominance dimension is represented at one end by a controlling figure and at the other end by a completely controlled figure. (Leão 2012, 28). The SAM is an instrument that can be used in countries of different cultures, since it is free from cultural influences and does not make use of language. (Bradley \& Lang 1994, 58). 


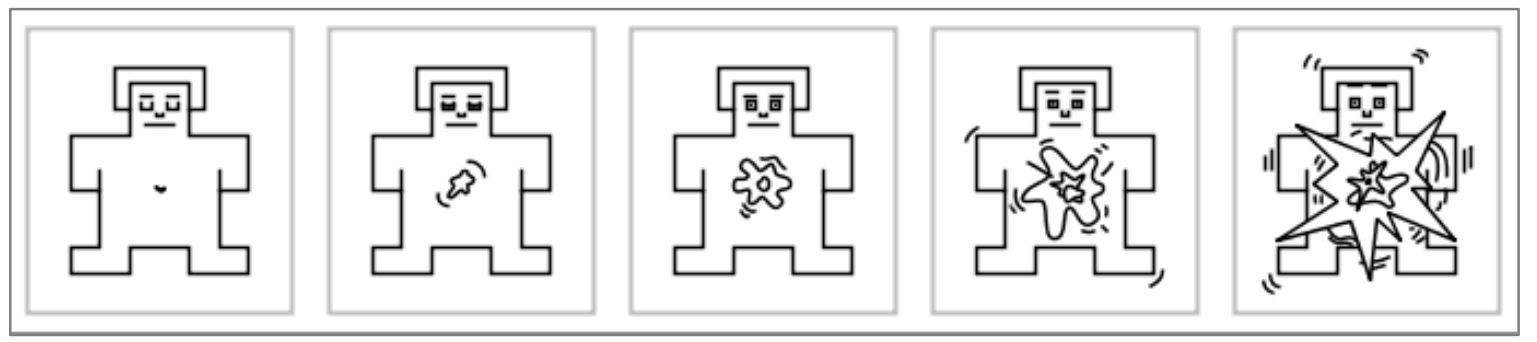

Figure 1 - Simplified SAM scale (Lang, 1980)

http://irtel.uni-mannheim.de/pxlab/demos/index_SAM.html

\section{Data analysis}

In this section we will analyse the set of results of the first eight questionnaires. In this sample there were three male and five female participants, with varied ages: (a) Two persons aged between 55 and 59; (b) Three persons aged between 60 and 65 and; (c)Three persons aged over 65 .

The results showed that six of the eight subjects had only other adults in their families, and the remaining two had adults and children. Hence, the study showed that none of the subjects lived independently. In terms of television habits, when asked: "How much TV hours do you watch daily?" with the selection of answers being: i) never; ii) less than an hour; iii) between one and two hours; iv) between two and three hours; v) more than three hours; it was observed that this sample of senior citizens watched one or more hours of television per day. When asked: "Where do you usually watch television" with the selection of answers being: i) living room; ii) bedroom; iii) kitchen; iv) other; the retrieved data showed that the spaces chosen to watch television by this sample were the living room, the kitchen (either alone or with company).

Seven of the eight participants had computers or other mobile devices (i.e. smartphones and tablets) but hardly or never use the computer. Even though seven of the participants have computers or other mobile devices, among the eight persons, six of them never use the computer; and we argue this can be explained by a low technological literacy. Regarding the physical conditions of our sample, none of them had hearing impairments that influenced the test and only 5 had higher visual impairments.

Concerning the cognitive capabilities, none of the eight participants has difficulties understanding and making themselves understood. Regarding memory and concentration capabilities, only one person had problems in concentrating and memorizing. This would be a concern in retrieving all the fundamental aspects of the audio visual materials showed, since if the subject were to be distracted the essential differences in the audio visual materials would not be noted. This would also reflect an important problem in the senior citizen's daily life, in gathering information and perceiving the world around him. 
All of the suggestions given about social services were considered important by the participants, however medical compensations and appointments were also considered important, as well as medical fees and insurance.

The results showed that, normally, the majority of the sample received information about the social services changes on television, confirming that the television is the greatest informative "friend" for the senior community. From the participant's point of view: 4 considered it a hard process to obtain information whereas 3 considered it an easy process to obtain information. It is important to note that the three participants, who found television an easy way to access this kind of information, have family members working in social services.

After dividing the group of eight senior citizens in two groups of four, we attributed to each group a theme (each theme included two videos with different approaches), which were: 1) the process of billing validation through the eFatura portal; and 2) the driving license regulated by a points system.

On the first theme, two videos were firstly presented to the subjects and after its visualization they answered a questionnaire. Whilst in the second group, which evaluated the second theme, participants had questions about the topic before watching the videos-and afterwards they confirmed their answers through the questionnaire.

On the first theme, the greatest difficulties shown by the senior citizens were the font size and the use of complex words. After watching the videos none of the four persons in the group were able to reproduce the information that the videos presented. Consequently, we can conclude that it is a difficult process, because the content was showcased as a tutorial, and therefore would oblige the senior citizens to have a certain level of literacy to replicate them. Usually, this kind of procedure is done by their relatives. When they were asked to choose between videos (same theme, different approaches), two senior citizens chose one and the other two senior citizens the other, but all gave the same justification: "More enlightening.".

On the second theme, the process was inverted: the subjects firstly were asked about the theme and afterwards they watched the videos. Regarding this question, although only two senior citizens had a driving license, all of the senior citizens responded correctly to the major points of the matter. Thus, all the four senior citizens knew the day on which the new system of driving license went active (1st July of 2016), and how many points would be attributed to each driver (12). They also knew, where to check the points that they had ('Portal de Contra-ordenações Rodoviárias').

When the senior citizens were asked about the quantity of points that would be removed if they drove under drug or alcohol influence, two of four participants did not know the answer. One of the senior citizens, who did not know the answer, had driving license and the other did not. Based on these results, we conclude that the senior citizens can be 
informed about a subject that is not directly related to them through the use of television programs that are carefully designed with their ages in mind. When participants were asked to choose between the two videos (same theme, different approaches), all of the senior citizens chose the same video, because they thought it was more simple, enlightening, contained more information and considered also that the presence of a presenter helped to understand the video. The senior citizens preferred a human presence rather than an animated presence.

\section{Conclusions}

Throughout this project, we firmly believe that interactive social services would become a 'must-have' in the lives of senior citizens, for all the benefits it brings to them. As we stated and defended, an easy access to this kind of services would be a good mechanism, since the majority of senior citizens do not interact with the Internet, due to the reasons stated before-hand, this applying to the senior citizens in this study. Reinforcing these services will contribute to the welfare and overall social inclusion of older people, and potentially facilitate the mental well-being of senior citizens. As shown in the results of this studied group of senior citizens, we can dismiss the part of information given by Internet, because all of the subjects in the study admitted not to use it and, consequently, they do not obtain any social service information by it.

We can conclude that physical and cognitive problems are of the most importance for the learning capabilities of senior citizens. The participants considered it easy to obtain information on the social services when their family was connected to those services; but the opposite was reported by those who did not have workers on social service in their family. For those senior citizens, to obtain such information is currently incredibly difficult. Even if some social services are not directly connected to their welfare, older people, as highlighted by this study, like to be informed of the overall new information of the remaining services. Participants suggested they like to be aware of all the new changes that are happening in society, so they can create a conversation about it with others. As shown in the results of this studied group of senior citizens.

Considering the classification of audio visual materials, it is noted that senior citizens in our study only had two standards, they liked it and considered it good or they hated it and considered it bad. When we applied the SAM (Self-Assessment Manikin) to further explore this issue we obtained neutral results on this matter (the participants always selected the same drawing). It is also important to refer that when two videos were showed one after the other, the participant had a tendency to grade and classify them on equal terms, even if they were substantially different at visual and audio level.

We can also state that senior citizens do not give too much importance to the graphical part of a product (its appearance), if the information is clear. The overall impression of an audio visual material can be justified by the proximity with the researcher, taking in mind the researcher's feelings on the matter. Even if the matter at hand is beyond their 
knowledge, participants reported that the information on the video was well distributed and understood.

As the researcher engaged with the senior citizens it is to be noted that, if a researcher has the need to make a questionnaire to senior citizens, they should select a questionnaire of open response, because senior citizens have the tendency to choose whatever the researcher states, even if the statements are false. This is in regard to the research group's experience with this project.

The creation of audio-visual materials regarding these social services has to be properly done in order to meet the needs of senior citizens. Some useful principles that we found as an outcome of this study are: good sound quality, good image quality, using simple words that are easy to understand and taking into account the font size (over 18). Using a human presenter, also, assisted knowledge transfer and senior citizens as a result are more likely to better understand the topics that are presented.

With the examples that we mentioned in this project, we can then conclude that in this research sample of senior citizens, there is still a big dependency of other to conclude many tasks, in several situations as was showed.

The results show that there is potential in this methodology's guide-lines for the development of audio visual contents for this target audience, to be integrated and considered for the daily dynamics of television. Therefore, with the development of this subject we hope that Private and Non-Private Organizations will take these "guidelines" in mind in order to reach better this special population segment.

\section{Acknowledgements}

The research leading to these work has received funding from Project 3599 - Promover a Produção Científica e Desenvolvimento Tecnológico e a Constituição de Redes Temáticas (3599-PPCDT) and European Commission Funding FEDER (through FCT: Fundação para a Ciência e Tecnologia I.P. under grant agreement no. PTDC/IVCCOM/3206/2014).

\section{References}

Abreu, J. (2007). Design de Serviços e Interfaces num Contexto de Televisão Interactiva (doctoral dissertation) [online] Departamento de Comunicação e Arte. Universidade de Aveiro, Aveiro, Portugal. Available at http://hdl.handle.net/10773/1259_Accessed 22 November 2016

Abreu, J. T. F., \& Silva Branco, V. A. (1998). Os rumos e as faces da Televisão Interactiva (White paper) [online]. December. Available at http://www.bocc.uff.br/pag/abreuferraz-rumos-faces-TV_I_final.pdf Accessed 22 November 2016 
Bradley, M. M., Lang, P. J. (1994). Measuring emotion: The self-assessment manikin and the semantic differential. Journal of Behavior Therapy and Exp. Psychiatry, 25 (1), pp. 49-59. Doi: http://dx.doi.org/10.1016/0005-7916(94)90063-9

Caldas, Ana Catarina Silva (2014). Tutoriais Audiovisuais para o Uso das TIC pelo Cidadão Sénior (master's dissertation) [online]. Departamento de Comunicação e Arte. Universidade de Aveiro, Aveiro, Portugal. Available at http://hdl.handle.net/10773/13863_Accessed 22 November 2016

Cardoso, Andrea Ferreira (2009). Particularidades dos idosos: uma revisão sobre a fisiologia do envelhecimento. Revista Digital Buenos Aires, 130 (13), p. 130 Available at http://www.efdeportes.com/efd130/idosos-uma-revisao-sobre-a-fisiologia-doenvelhecimento.htm_Accessed 22 November 2016

Carneiro et al. (2012). O Envelhecimento da População: Dependência, Ativação e Qualidade (Research Report) Universidade Católica Portuguesa, Available at http://www.qren.pt/np4/np4/?newsld=1334\&fileName=envelhecimento_populacao.pdf Accessed 22 November 2016

Czaja, S., \& Sharit, J. (2012). Designing Training and Instructional Programs for Older Adults. Florida, USA: CRC Press.

European Commission (2008). Digital Literacy European Commission Working Paper and Recommendations from Digital Literacy High-Level Expert Group [online]. Available at http://www.ifap.ru/library/book386. pdf_Accessed 22 November 2016

Ferreira, S. (2013). Tecnologias de Informação e Comunicação e o Cidadão Sénior. (doctoral dissertation). Departamento de Comunicação e Arte. Universidade de Aveiro e Universidade do Porto, Portugal. Available at http://hdl.handle.net/10773/12336_Accessed 22 November 2016

Fisk, A., Rogers, W., Charness, N., Czaja, S., \& Sharit, J. (2009). Designing for older adults Principles and Creative Human factors Approaches. Florida, USA: CRC Press.

Lang, P. J. (1980). Behavioral treatment and bio-behavioral assessment: computer applications. In J. B. Sidowski, J. H. Johnson, \& T. A. Williams (Eds.), Technology in mental health care delivery systems (pp. 119-I37). Norwood, NJ: Ablex.

Leão, Luisa Isabel Ribeiro (2012). Indução da emoção através de estímulos emocionógenos gerados por computador (master's dissertation). Instituto Superior de Ciências da Saúde, Portugal.

McLuhan, M. (1962). The Gutenberg galaxy: the making of typographic man.

Toronto, Canada: University of Toronto Press.

Oliveira, R. (2014). Promoção da acessibilidade em iTV para públicos com défice visual. Revista Prisma, $n^{\circ} 23$, pp. 139-158. Available at

http://revistas.ua.pt/index.php/prismacom/article/view/2896/pdf_15 Accessed 22 November 2016

Pereira, C. (2010). O contributo das TIC para a Qualidade de Vida de pessoas idosas. Departamento de Didática e Tecnologia Educativa e Departamento de Comunicação e Arte. Universidade de Aveiro, Aveiro, Portugal. Available at https://ria.ua.pt/bitstream/10773/1420/1/2010000698.pdf Accessed 22 November 2016 
Santos, R. (2003). Sobre Marshall Mcluhan [blog]. Available at http://industriasculturais.blogspot.pt/2003/12/sobre-marshall-mcluhan-partir-de-em.html_Accessed 22 November 2016

Silva, Alexandra Isabel Pereira (2002). Televisão Interativa: Impacto e procura de um novo perfil de utilizador [Research report]. Universidade Fernando Pessoa, Porto, Portugal. Available at http://homepage.ufp.pt//mbg/monografias/isabel.pdf Accessed 22 November 2016

Silva, T. E. (2014), Identificação de utilizadores seniores em aplicações de iTV: uma matriz de decisão tecnológica (doctoral dissertation), Universidade de Aveiro, Aveiro, Portugal.

Teixeira, Liliana Márcia Fernandes (2010). Solidão, Depressão e Qualidade de Vida em Idosos: Um Estudo Avaliativo Exploratório e Implementação-Piloto de um Programa de Intervenção (doctoral dissertation). Universidade de Lisboa, Lisboa, Portugal. Available at http://repositorio.ul.pt/jspui/bitstream/10451/2608/1/ulfp037460_tm_tese.pdf Accessed 22 November 2016

Violante et al. (2015). Televisão Interativa (website). Instituto Superior Técnico - Taguspark. 03-01-2016. Available at http://web.ist.utl.pt/ ist172413/cmul/\#autores Accessed 22 November 2016

Wolton, D. (1996). O elogio do grande público: uma teoria crítica da televisão. São Paulo: Ática.

Zaphiris, P., Ghiawadwala, M., \& Mughal, S. (2005). Age-Centered Research-Based Web Design Guidelines. In CHI'05 extended abstracts on Human factors in computing systems (pp. 1897-1900). New York, USA: ACM. Doi:

http://dx.doi.org/10.1145/1056808.1057050

Mariana Carlos is a MsC student in Communication Multimedia at the University of Aveiro. Her research focus on the development of content about social services for itv addressed to senior citizens' viewers.

Email: mariana.carlos@ua.pt

Telmo Eduardo Silva is an Assistant Professor at the Department of Communication and Arts in University of Aveiro and he is also the coordinator of the master in Multimedia Communication. He got his graduation and Master's degree in Electronic, Telecommunication and Informatics by the University of Aveiro, Portugal and a $\mathrm{PhD}$ in Information and Communication in Digital Platforms by the University of Aveiro and University of Porto. His research interests are: Design, development and evaluation of iTV services; Computer networks; Web applications based on Content Management Systems.

Email: tsilva@ua.pt 